J. Dairy Sci. 90:4004

(c) American Dairy Science Association, 2007.

\title{
Erratum
}

\section{Effect of an Intramammary Teat Seal and Dry Cow Antibiotic in Relation to Dry Period Length on Postpartum Mastitis}

E. A. Berry and J. E. Hillerton

J. Dairy Sci. 90:760-765

On page 761, the final paragraph under Statistical Analysis states

"Quarter interdependence was not considered in the analysis because our previous study (Berry et al., 2003) had demonstrated that this was not a factor if all quarters within the cow were treated prophylactically and this had not been taken into consideration by other studies on internal teat sealants (Huxley et al., 2002; Berry et al., 2003; Godden et al., 2003).”

However, the Huxley et al. (2002) study (J. Dairy Sci. 85:551-561) was misquoted as not including cow in the analysis for quarter interdependence and using cow as a fixed variate in their model. In fact, the Huxley et al. (2002) paper states

"Treatment group was used as an exposure variable and cow identity was fitted as a random effect to account for the clustering of quarters within cows ..."

The authors regret the error. 